\title{
Mandibulanın kondil ve ramus uzunlukları temporomandibular eklem düzensizliklerinde(TMD) predizpozan faktörler midir? Panoramik radyografi çalışması
}

\section{Are condylar and ramus heights of mandible predisposing factors for temporomandibular joint disorders(TMD)? A panoramic radiographical study}

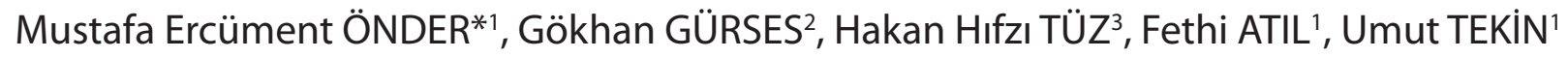

'Kırıkkale Üniversitesi, Diş Hekimliği Fakültesi, Ağız Diş Çene Cerrahisi ABD, Kırıkkale/TÜRKiYE

${ }^{2}$ Necmettin Erbakan Üniversitesi, Diş Hekimliği Fakültesi, Ağız Diş Çene Cerrahisi ABD, Konya/TÜRKiYE

${ }^{3}$ Hacettepe Üniversitesi, Diş Hekimliği Fakültesi, Ağız Diş Çene Cerrahisi ABD, Ankara/TÜRKiYE

\section{öz}

Amaç: Temporomandibular eklem düzensizlikleri (TMD) oral ve maksillofasiyal bölgede sıklıkla karşılaşılan problemlerdendir. TMD'nin meydana gelmesi ile ilgili pek çok teori mevcuttur. Anatomik koşulların da hastalığın etiyolojik sebeplerinden olabileceği düşünülmektedir. Bu çalışmada, TMD semptomu olan ve herhangi bir TMD semptomu göstermeyen hastalarda mandibular kondil, ramus uzunlukları ve birbirlerine olan oranları ölçülerek, etiyolojik faktör olarak değerlendirilip değerlendirilemeyeceği araştırmak amaçlanmıştır.

Gereç ve Yöntemler: Çalışma kliniğimize başvuran yaşları 15-60 arası 59 hasta ( $n=40$; semptomatik, $n=19$; asemptomatik) üzerinde yapılmıştır. Semptomlu hastalar her iki tarafta (bilateral) temporomandibuler bölgede krepitasyon, kliking ve ağrı şikâyetlerinden en az biri için kliniğimize başvuran hastalar arasından seçilmiştir. Kontrol grubunda yer alan hastalar ise temporomandibuler eklem bölgesinde herhangi bir şikâyeti olmayan semptomsuz hastalar arasından seçilmiştir. Ramus ve kondil uzunlukları standart panaromik radyografiler üzerinden değerlendirilmiştir.

Sonuç: Her iki grup arasında yapılan değerlendirmeler sonucunda TMD olan hastaların kondil ve ramus boyu uzunluklarının TME bölgesinde şikayeti olmayan hastalara göre daha uzun olduğu istatistiksel olarak tespit edilmiştir. Ancak kondil/ramus oranları arasında istatistiksel olarak anlamlı bir fark bulunmamıştır.

Sonuç: Kondil ve ramus uzunluklarının TMD olan hastalarda daha uzun olduğu, etiyolojik faktör olarak belirtilebileceği söylenebilir.

Anahtar Kelimeler: Temporomandibular eklem; kondil uzunluğu; ramus uzunluğu; predispozan

Sorumlu yazar*: Mustafa Ercüment ÖNDER , Kırıkkale Üniversitesi, Diş Hekimliği Fakültesi, Ağız Diş Çene Cerrahisi ABD, Kırıkkale/TÜRKiYE E-posta: ercuonder@gmail.com 


\section{ABSTRACT}

Aim: TMJ disorders are one of the most common problems in oral and maxillofacial region. There are many theories about the emergence of the temporomandibular disorders (TMD). Anatomic structures may be predisposing factors. The purpose of the present study is to consider the evaluation of the length of condyle, ramus and condyle/ramus ratio by using panoramic radiograph as an etiological factor for TMD.

Material and Methods: The research consisted of 59 patients aged 15 to 60 ( $n=40$; symptomatic, $n=19$; asymptomatic). The study group which constituted with the patients who had at least one of the TMD symptoms as; crepitation, clicking and pain. The control group consisted with individuals with noTMD symptoms. Ramus and condyle heights were evaluated with the panoramic radiograph measurements.

Results: The results showed that, the condyle and ramus heights were statistically significant longer in the study group than the control group. Nevertheless there were no statistically significant difference between the ratios of condyle and ramus heights.

Conclusion: Condyle and ramus heights, which assessed longer in the patients with TMD, may indicate as an aetiological factor.

Keywords: Temporomandibular joint; Height of Condyl; Height of Ramus,; Predisposing Factor

\section{Giriş}

Temporomandibular eklem (TME) dış kulak yolunun hemen önünde, temporal kemiğin altındaki mandibular fossa ile mandibula kondili arasında yer almaktadır. Morfolojik olarak kişiden kişiye ve aynı kişide sağ ve sol eklemlerin birbirlerine göre değişkenlik gösterdiği, menteşe ve kayma hareketi yapan, kayma eksenli bileşik bir eklemdir. TME mandibula, temporal kemik, artiküler disk gibi osseöz komponentin yanında ligament, eklem kapsülü ve kas bağlantılarını içeren yumuşak doku komponentlerinden oluşan diartrodial bir eklemdir [1].

Yale ve arkadaşlarına göre bütün kondillerin $\% 97,1^{\prime} i$ frontal profillerine bağlı olarak dört gruptan birine dâhil edilmektedir. Bunlar ya düz, dışbükey, köşeli ya da yuvarlak olarak tanımlanmaktadır[2]. Eklem yüzeylerine gelen yükler kondil şekillenmesine etki etmektedir. Kondilin şekli, Schüller projeksiyonu ile alınan radyografik görüntüleme yöntemi ile tespit edilmektedir. Kondil tiplerinin TME hastalıklarında etiyolojik rol oynadığı tespit edilmemiş olup bazı in vitro çalışmalar osteoartritis sonucu kondil başının morfolojik değişikliğe uğrayabileceği gösterilmiştir [3].

TME'nin artiküleryüzeyleri fibröz konnektif dokudan oluşmuştur. Fibröz konnektif doku zamanla gelişen aşınmaya, hyalin kartilaja göre daha az meyilli olup, dejeneratif değişikliklere daha dirençlidir ayrıca fibröz dokunun yenilenme kabiliyetinin hyalin kartilajdan daha iyidir. Eklemin artikülâsyon yüzeyleri değişen miktarlarda kondrosit, proteoglikan, esnek lifler ve oksitalan lifleri içeren yoğun bir bağ doku ile kaplıdır [4]. Baskılayıcı yükleri soğurup dağıtabilen kıkırdaklar yapısal olarak fazla miktarda su bulundurur ve tip II kollajen ağı içinde yüksek molekül ağırlıklı kondroitin sülfat içerir [5]. Eklem üzerinde düşük seviyedeki fonksiyonel intiyaçlar tip I kollajen miktarında artış ve tip || kollajen miktarında azalmaya yol açar [6].

Aşındırıcı değişikliklere uğrayan eklemlerdeki trabeküler kemik oranı (\%21) ve toplam kemik miktarı (\%54), bu tip değişikliklere uğramamış benzer kondillerin kemik hacimlerine (\%15\%40) göre belirgin derecede fazladır. Bu nedenle dejeneratif değişimler çoğunlukla eklem yüzeylerine gelen ve fizyolojik olmayan yükler ile ilişkilidir [7].

TME, vücudun diğer eklemlerinden farklı özellikleri olan, kompleks bir yapıdır. Her iki eklem ayrı birer fonksiyonel birim gibi hareket etse de, bu iki eklem mandibula ile birbirine bağlı olduğu için birindeki hareket veya fonksiyonel değişiklikler diğerini de etkileyerek temporomandibular eklem düzensizlikleri (TMD) oluşmasına neden olmaktadır. Dolayısıyla TME'nin normal fonksiyonu için bilateral senkronizasyon şarttır [8].

TMD etyolojisi hakkında önceden sunulan teoriler mekanik yer değiştirme teorisi, travma teorisi, biyomedikal teori, osteoartritik teori, kas teorisi gibi biyomedikal model üzerine kurulmuştur. Fakat bu teoriler TMD sistematiğini ve yapısal unsurlarını tam olarak açıklamaktan uzak kalmışır. Bunun üzerine daha genişletilmiş olarak maloklüzyon, kötü alışkanlıklar, travma, psikolojik faktörler, postüral faktörler, gelişimsel ya da kazanılmış bozuklukları kapsayan biyofizikososyal teori ortaya atılmıştır [9]. 
Habets ve arkadaşları kondiler asimetri ve TMD arasındaki ilişkiyi tanımlamak için bir teknik tanımlamışlardır. Bu teknikte sağ ve sol mandibular kondil ve ramus yükseklikleri incelenmektedir [10].

Bu çalışmanın amacı mandibulanın yaptığı sınıf-3 kaldıraç hareketinden yola çıkarak, direnç kolunun (ramus-kondil uzunlukları) uzun ya da kısa olmasının, gerekli olan kas gücü miktarında bir değişime yol açacağını değerlendirerek; genetik olarak miras bırakılan morfolojik yapı ve uzunlukların TMD için bir etiyolojik faktör olabileceğini istatistiksel açıdan ortaya koymak ve bilimsel literatüre katkı sağlamaktır.

\section{Gereç ve Yöntemler}

Çalışma, Selçuk Üniversitesi Diş Hekimliği Fakültesi, Girişimsel Olmayan Klinik Araştırmalar Değerlendirme Komisyonu'nun 2016/07 sayılı toplantısında alınan izin ile yapılmıştır. Çalışmaya ait kuvvet analizi "Power and Precision Sotfware" (Biostat, Anklewood, NJ, ABD) isimli yazılımla yapılmıştır. Bu analizin sonuçlarına göre çalışmanın gücünün $0,8(a=0,05)$ olması kaydıyla her iki grupta toplam denek sayısının 60 adet olması ön görülmüştür. Çalışma grubu 40 hastadan, kontrol grubu ise 20 hastadan oluşturulmuştur. Çalışma kliniğimize başvuran yaşları 15-60 arası değişen 40'ı semptomlu 20'si semptomsuz toplam 60 hasta üzerinde yapılmıştır. Semptomlu hastalar her iki tarafta (bilateral) temporomandibuler bölgede krepitasyon, kliking ve ağrı şikâyetlerinden en az biri için kliniğimize başvuran hastalar arasından seçilmiştir. Kontrol grubu olan hastalar ise temporomandibuler bölgesinde herhangi bir şikâyeti olmayan semptomsuz hastalar arasından seçilmiştir.

Düzgün maksiller ve mandibular ark yapısına sahip olan, üçüncü molar dişleri dışında diğer dişleri ağızda bulunan, klinik olarak düzgün fasiyal simetrisi bulunan, mandibulada deviasyonu olmayan hastalar çalışma grubuna dahil edilmiştir. Çift taraflı eklem rahatsızlığının olan, TMD belirti veya bulgulardan en az birinin bulunan hastalar çalışma kapsamındadır. Daha önce herhangi bir eklem tedavisi görmemiş olan, geçmişte travma hikayesi olmayan, ortodontik ve protetik tedavi görmemiş, maksillofasiyal ve plastik cerrahi operasyonu geçirmemiş, herhangi bir sistemik rahatsızlığının olmayan hastalar çalışmaya dahil edilmiştir.

Hatalı pozisyonlanan, ölçüm yapılırken kullanılan anatomik noktaları net olarak belli olmayan radyografiler çalışma ve kontrol gruplarına dahil edilmemiştir.

Hastalardan fakültemizde rutin olarak alınan dijital panoramik radyografi üzerinde ölçümler yapılmıştır. Panoramik radyograf standart koşullarda ve aynı operatör tarafından çekilmiştir. Panoramik radyograf dudaklar rahat pozisyonda iken ve kafa Frankfurt horizontal düzlemine paralel hale getirilerek çekilmiştir.Bu tekniğegöremandibulaüzerindebelirlianatomik noktalar belirlenmiş ve belirlenen noktalar arası mesafe dijital ortamda ölçülerek veriler elde edilmiştir. Radyografiler Instrumentarium Dental; Tuusula, FiNLAND(57-85 kV/2-16 mACCD $96 \mu \mathrm{m}$, magnifikasyon değeri 1.14.1), PAX UNI 3-D Vatech; Seoul,KOREA(60-80 kV/8-10 mA-CMOS $100 \mu \mathrm{m}$, magnifikasyon değeri 1.32.1) panoramik radyografi cihazlarıyla alınmıştır. Ölçümler aşağı belirtilen yöntem ile yapılmış olup tekniğin tasarımında kullanılan anatomik noktalar şunlardır (Resim 1):

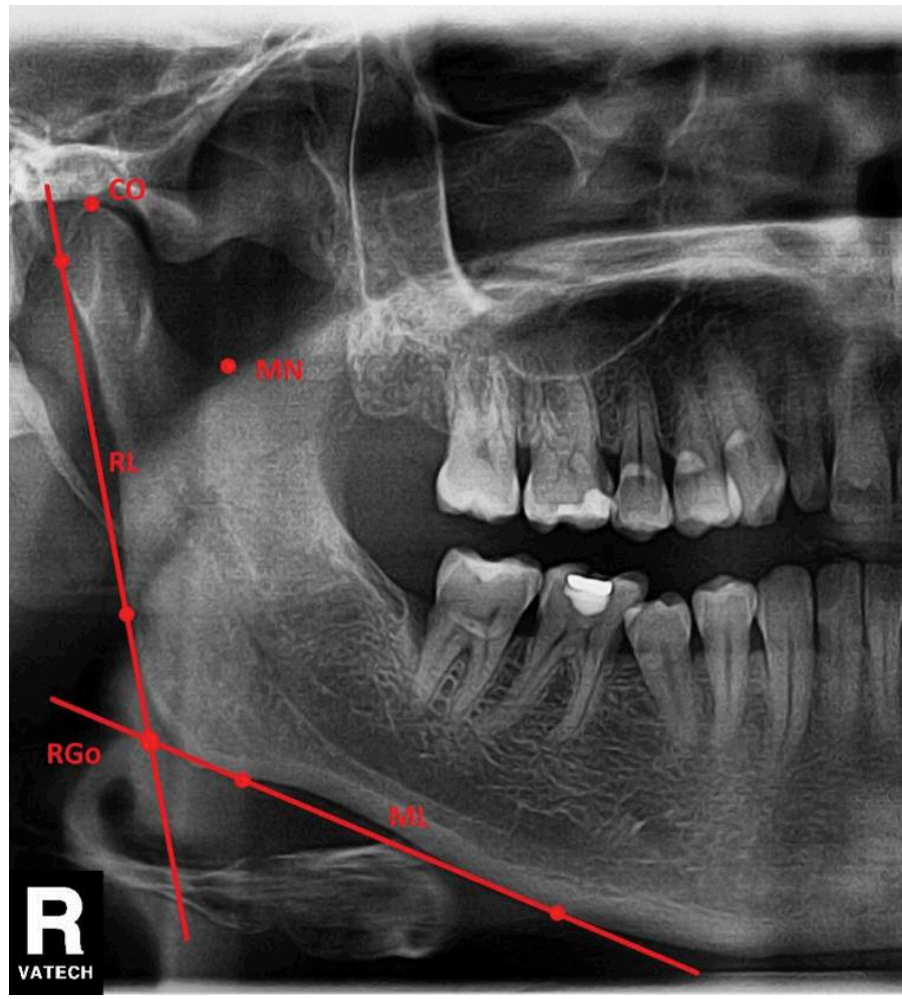

Resim 1: Panoramik radyografi üzerinde belirlenen anatomik noktalar CO: Kondilin en yüksek noktası

MN: Mandibuler notch

RL: Ramal line (mandibulanın en posterior iki noktasını birleştiren izafi doğru)

ML: Mandibular line (mandibula korpusunun en inferior iki noktasını birleştiren izafi doğru)

RGo: Relative gonion

RL doğrusuna dik, kondil başının tepe noktasından geçecek şekilde bir doğru daha çizilerek bu doğruyla RL doğrusun kesişim noktası N1 olarak belirlendi(Resim 2). 


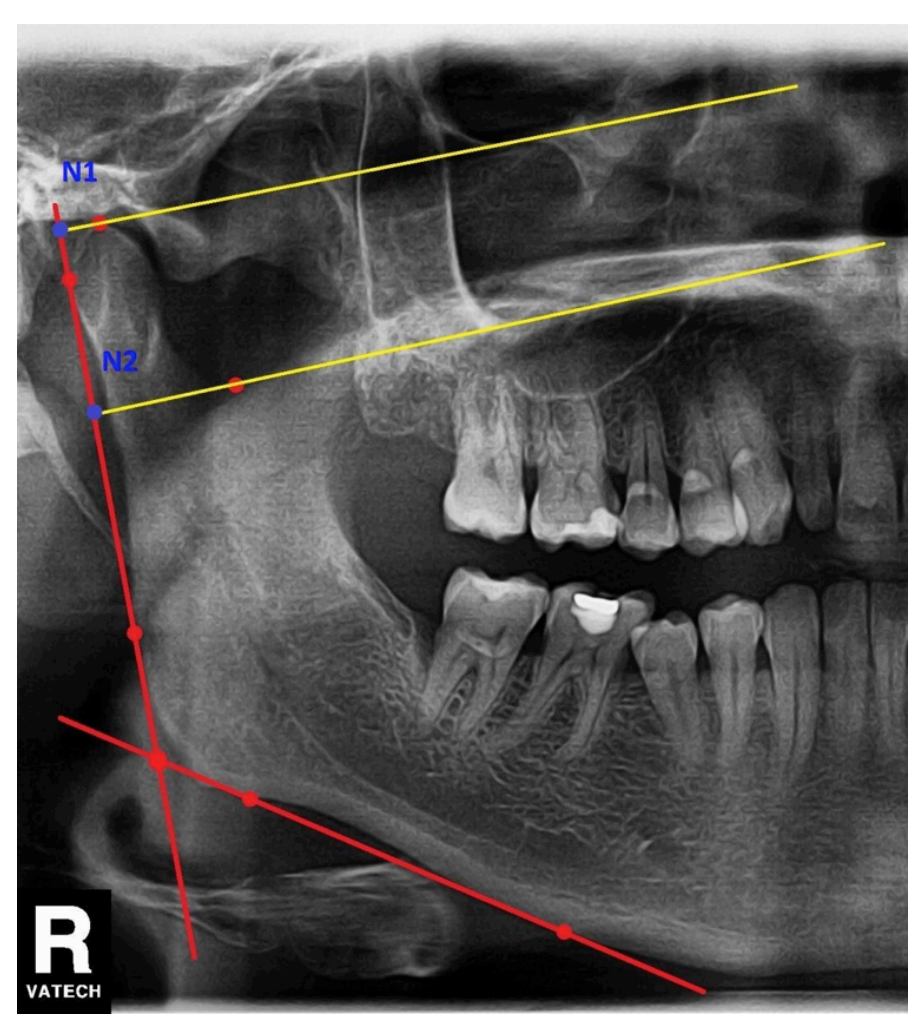

RL doğrusuna dik, MN(mandibular notch)'den geçecek şekilde bir doğru çizilerek ve bu doğruyla $R L$ doğrusunun kesişim noktası N2 olarak belirlendi(Resim 2).

N1 - N2 noktaları arası kondil uzunluğu, N2 - RGo noktaları arası ise ramus uzunluğu olarak hesaplanmıştır.

Buçalışmada parametrikolmayanverilerin değerlendirilmesinde ve iki ayrı grubun belli bir değişkene ait ortalamalarını karşılaştırmakiçin kullanılan Mann-Whitney U testi kullanılmıştır. $\mathrm{Bu}$ veriler, SPSS 15.0 paket programıla değerlendirilmiştir. Gruplar arası farklıık incelenirken; anlamlılık seviyesi olarak 0,05 kullanılmış olup $p<0,05$ olması durumunda gruplar arası anlamlı farklılığın olduğu, $p>0,05$ olması durumunda ise gruplar arası anlamlı farklılığın olmadığı belirtilmiştir.

\section{Bulgular}

Kondil boyu incelendiğinde çalışma grubundaki ölçümler ortalama $18.02 \pm 3.54$, kontrol grubunda $15,98 \pm 3,43$ olarak bulunmuştur. Bu farklılık istatistiksel olarak anlamlıdır $(p=0,009)$ (Tablo 1).

Resim 2: Kondil uzunluğunu ölçmek amacıyla belirlenen N1-N2 noktaları

\begin{tabular}{|c|c|c|c|c|c|c|c|c|c|c|}
\hline & & \multicolumn{6}{|c|}{ Gruplar } & \multicolumn{3}{|c|}{ Mann Whitney U Testi } \\
\hline & & Sayı & Ortalama & Ortanca & En $\mathrm{Az}$ & En Çok & SS & Sıra Ort. & $U$ & $\mathrm{p}$ \\
\hline \multirow{3}{*}{ Kondil } & Semptomlu & 80 & 18.02 & 17.85 & 11.60 & 31.30 & 3.54 & 65.14 & \multirow{3}{*}{1068.5} & \multirow{3}{*}{0.009} \\
\hline & Semptomsuz & 40 & 15.98 & 16.40 & 7.30 & 22.60 & 3.43 & 47.62 & & \\
\hline & Toplam & 120 & 17.36 & 17.50 & 7.30 & 31.30 & 3.62 & & & \\
\hline \multirow{3}{*}{ Ramus } & Semptomlu & 80 & 39.68 & 38.90 & 26.50 & 50.70 & 4.58 & 64.29 & \multirow{3}{*}{11365} & \multirow{3}{*}{0.027} \\
\hline & Semptomsuz & 40 & 37.41 & 37.80 & 24.70 & 45.30 & 4.73 & 49.41 & & \\
\hline & Toplam & 120 & 38.95 & 38.70 & 24.70 & 50.70 & 4.73 & & & \\
\hline
\end{tabular}

Ramus boyu incelendiğinde çalışma grubundakiölçümler ortalama $39.68 \pm 4.58$, kontrol grubunda 15,98 $\pm 4,73$ olarak bulunmuştur. Bu farklılık istatistiksel olarak anlamlıdır $(p=0,027)$ (Tablo 1).
Kondil/Ramus oranları incelendiğinde ise çalışma grubundaki ortalama $0.46 \pm 0.11$ olarak bulunmuştur. Bu farklılık istatistiksel açıdan anlamlı bulunmamıştır ( $p=0,241)$ (Tablo 2).

\begin{tabular}{|c|c|c|c|c|c|c|c|c|c|c|}
\hline & & \multicolumn{6}{|c|}{ Grup } & \multicolumn{3}{|c|}{ Mann Whitney U Testi } \\
\hline & & Sayı & Ortalama & Ortanca & $\mathrm{En} \mathrm{Az}$ & En Çok & SS & Sira Ort. & $U$ & $p$ \\
\hline \multirow{3}{*}{ Kondil /Ramus } & Semptomlu & 80 & 0.46 & 0.44 & 0.29 & 0.7 & 0.11 & 62.04 & & \\
\hline & Semptomsuz & 40 & 0.43 & 0.435 & 0.24 & 0.57 & 0.08 & 54.14 & 1316.5 & 0.241 \\
\hline & Toplam & 120 & 0.45 & 0.44 & 0.24 & 0.7 & 0.10 & & & \\
\hline
\end{tabular}




\section{Tartışma}

TMD oluşmasında çevresel ve genetik faktörler rol oynamaktadır. Hastalık etiyolojisinde travma, enfeksiyonlar ve gelişimsel anomaliler rol oynamaktadır [11]. TMD etiyolojisinin multifaktöriyel olduğu düşünülmektedir. Kas hiperaktivitesinin ve parafonksiyonel alışkanlıkların TMD'nin oluşmasında en önemli faktörler arasında yer almaktadır. Kondiler asimetri eklem artiküler yüzeylerin aşırı yüklenmesine bağlı olarak yumuşak ve sert doku yüzeyinde özellikle farklılaşmayan mezenşimal hücrelerinin bulunduğu tabakada meydana gelen değişikliklere bağlı olarak oluştuğu gözlenmiştir[8]. Kas hiperaktivitesine bağlı olarak artiküler yüzeylerde meydana gelen aşırı yüklenme, hastalarda osteoartrit oluşmasına neden olmaktadır. Artiküler yüzeyinde meydana gelen aşırı yük eklem yumuşak doku komponentlerinde kalınlaşmaya neden olmakta ve kondiler asimetri kas hiperaktivitesine bağlı olarak oluşmaktadır. Eklem bölgesinde meydana gelen bu değişiklik adaptasyon kapasitesini aşana kadar semptomsuz devam ederken adaptasyon kapasitesi aşıldığı andan itibaren hastalarda semptomlar ortaya çıkmaktadır[8].

Panoramik radyografi, 1960 yılında diş hekimliği alanında kullanıma sunulduğu andan itibaren günümüze kadar mandibulada sağ ve sol taraftaki kondil ramus ve total yükseklik farkını ve asimetrisini ve TMD tanımlamada kullanılmıştır. Birçok çalışma TMD’nin ilk değerlendirmesi yapmak için bu tekniğin kullanılması gerektiğini vurgulamıştır. Panoramik radyografiler asimetri değerlendirmesinde kabul edilebilir sonuçlar sunmaktadır ayrıca yapılan inceleme minimal invaziv sayılmakta ve hastalar düşük doz radyasyona tabi tutularak elde edilen veriler TMD hakkında detaylı bilgi vermektedir [12]. TMD, etiyolojisi, morfolojisi, tedavisi yönünden çok kapsamlı bir konudur. Bu çalışmada kondil-ramus uzunlukları ve kondil/ramus oranı radyolojik veriler üzerinden değerlendirilmiştir. Yapılan literatür taramasında, TMD ve kondil-ramus boyu arasında, etiyolojik ilişki yönünden değerlendirme yapan bir çalışmaya rastlanılmamıştır. Benzer çalışmaların da sayısı kısıtlı olup, aşağıda örnekleri verildiği üzere bu çalışmalar daha çok radyografi üzerinde yapılan ölçümlerin güvenirliği konusundadır.

TMDolanhastalardakondilinyerdeğiştirmesinideğerlendirilerek yapılan bir çalışmada; çalışma grubunda yer alan hastalarda kontrol grubuna göre kondilin vertikal ve horizontal olarak anlamlı derecede yer değiştirdiği tespit edilmiştir [13].
Posterior çapraz kapanış bulunan hastaların kondiler asimetrileri baz alınarak yapılan bir diğer çalışmada ise; genel, cinsiyet ve taraf bazlı değerlendirmelerde istatistiksel olarak anlamlı bir fark bulunmamıştır [14].

Tronje ve arkadaşlarının panoramik radyografinin doğruluğunu değerlendirmek üzere yaptığı çalışmada panoramik radyografilerin vertikal değerlendirmeler için kullanılabileceği ancak horizontal değerlendirmelerde kullanılmaması gerektiğini vurgulamışlardır. Panoramik radyografide yapılan vertikal ölçümlerin doğruluğunun \pm \%10 olduğunu belirtmişlerdir [15].

Habets ve arkadaşlarının asemptomatik TMD bulunan hastalar üzerinde yaptığı çalışmada hastalarda kondiler asimetri olduğunu saptamıştır. Kondil yüksekliğinin ölçmeye yönelik yaptığı bu çalışmada mandibulanın orijinal pozisyonundan $10 \mathrm{~mm}$ ya da daha az hareket ettirilmesi sonucunda sağ ve sol taraftaki kondil yükseklik farkı \%6'dan az bulunmuştur. Sonuç olarak sağ ve sol kondil yükseklik farkı \%6'dan az ise bu panoramik radyografi çekiminden kaynaklanan teknik hata olarak nitelendirilirken \%6'dan fazla fark saptanırsa kondiler asimetri varlığı düşünülmelidir [16].

Bezuur ve arkadaşlarının miyojen kökenli TMD hastalar ile artrojen kökenli TMD hastalarının kıyaslanmasına dayalı olarak yaptığı çalışmada kas kökenli TMD bulunan hastalarda vertikal kondil yüksekliğinin daha fazla olduğu belirlenmiştir [17].

Son yıllarda, manyetik rezonans (MR) ile yapılan çalışmalarda, spesifik TMD grubunda, kondil yüksekliğinin azaldığı, disk yapısının da kısaldığı bildirilmektedir. Ancak çalışmanın MR ile yapılması kemiksel ölçümlerin hassasiyetini azaltacağını düşündürmektedir[18].

Yapılan bu çalışmada ise 80'i semptomlu, 40'ı semptomsuz toplam 120 TME değerlendirilmiş olup semptomlu TME'lerin kondil ve ramus uzunluklarının, semptomsuz TME'lere göre istatistiksel olarak daha uzun olduğu, semptomlu ve semptomsuz TME'lerdeki kondil/ramus oranlarında ise istatistiksel olarak bir farklılık olmadığı saptanmıştır.

Tüm yapılan değerlendirmeler ve klinik çalışmalar sonucunda TME hastalarının kondil ve ramus uzunlukları sağlıklı bireylere göre daha uzun olduğu söylenebilir. Bu bulgu, TMD'nin oluşmasında etkili olan etiyolojik faktörlerden biri olarak düşünülebilir. Fakat teorinin desteklenebilmesi için örnek sayısı arttırılmış; semptom, klinik ve radyografik görünüm olarak karşılaştırılmış çalışmalara gereksinim vardır. 


\section{Çıkar çatışması / finansal destek beyanı}

Bu yazıdaki hiçbir yazarın herhangi bir çıkar çatışması yoktur. Yazının herhangi bir finansal desteği yoktur

\section{Kaynaklar}

1. Özcan B. Bruksizme eşlik eden miyofasyal ağrı sendromlu ve temporomandibular rahatsızlığı olan hastalarda oklüzal splint ve tens tedavilerinin klinik ve ağrı eşiği üzerine olan etkinliklerinin karşılaştırılması. Uzmanlık tezi, Şişli Eftal Hastanesi Fizik Tedavi ve Rehabilitasyon Kliniği, İstanbul;2005.

2. Yale SH, Ceballos M, Kresnoff CS, Hauptfuehrer JD. Some observations on the classification of mandibular condyle types. Oral Surg Oral Med Oral Pathol 1963; 16: 572-77.

3. Gross A, Bumann A, Hoffmeister B. Elastic fibers in the human temporo-mandibular joint disc. Int J Oral Maxillofac Surg 1999; 28: 464-68.

4. Dijkgraaf LC, de Bont LG, Boering G, Liem RS. Structure of the normal synovial membrane of the temporomandibular joint: a review of the literature. J Oral Maxillofac Surg 1996; 54: 332-38.

5. Maroudas A. Physical chemistry and the structure of cartilage. J Physiol 1972; 223: 21-22.

6. Pirttiniemi $\mathrm{P}$, Kantomaa T. Electrical stimulation of masseter muscles maintains condylar cartilage in long-term organ culture. J Dent Res 1996; 75: 1365-71.

7. Bumann A, Roltzmann U; Çeviri Editörleri; Tüz H.H, Atıl F: Diş Hekimliği Renkli Atlası; Temporomandibular Eklem Bozuklukları, Fonksiyonel Tanı ve Tedavi Yöntemleri, 1. Baskı. İstanbul: Palme Yayıncılık; 2009: 76-79.

8. Wright E.F. Manual of Temporomandibular Disorders. 2nd ed. New Jersey: Wiley and Blackwell; 2010.

9. Bhat S. Etiology of temporomandibular disorders: the journey so far. International Dentistry SA 2011; 12: 88-93.
10. HabetsLL,BezuurJN,NaeijiM,HanssonTL.Theorthopantomogram, an aid in diagnosis of temporomandibular joint problems. II. The vertical symmetry. J Oral Rehabil 1988; 15: 465-71.

11. Persson M. Mandibular asymmetry of hereditary origin. Am J Orthod 1973; 63: 1-11.

12. Saglam AA, Sanli G. Condylar asymmetry measurements in patients with temporomandibular disorders. J Contemp Dent Pract 2004; 15: 59-65.

13. Padala S, Padmanabhan S, Chithranjan AB. Comparative evaluation of condylar position in symptomatic (TMJ dysfunction) and asymptomatic individuals. Indian J Dent Res 2012; 23:122.

14. Uysal T, Sisman Y, Kurt G, Ramoglu SI. Condylar and ramal vertical asymmetry in unilateral and bilateral posterior crossbite patients and a normal occlusion sample. Am J Orthod Dentofacial Orthop 2009; 136: 37-43.

15. Tronje G. Image distortion in rotational panoramic radiography. Tandlakartidningen 1983; 75 :88-91.

16. Habets LL, Bezuur JN, van Ooij CP, Hansson TL. The orthopantomogram, an aid in diagnosis of temporomandibular joint problems. I. The factor of vertical magnification. J Oral Rehabil 1987; 14: 475-80.

17. Bezuur JN, Habets LL, Hansson TL. The recognition of craniomandibular disorders; condylar symmetry in relation to myogenous and arthrogenous origin of pain. J Oral Rehabil 1989; 16: 257-60.

18. Ziang Z, Xieyi C, Qianyang X. Is Anterior Disc Displacement Without Reduction Associated With Temporomandibular Joint Condylar Height in Juvenile Patients Younger Than 20 Years? J Oral Maxillofac Surg 2015; 73: 843-49. 